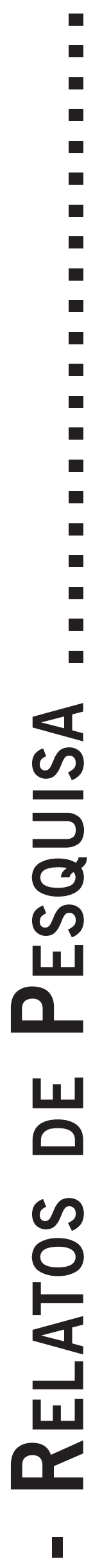




\title{
CONTEMPORANEIDADE E EXPERIÊNCIAS ANÔMALAS: DIMENSÕES PSICOSSOCIAIS DE VIVÊNCIAS CULTURALMENTE LIMÍTROFES ${ }^{1-2}$
}

\author{
Contemporaneity and Anomalous Experiences: \\ Psychosocial Dimensions of Culturally Frontier Experiences \\ Contemporaneidad y Experiencias Anómalas: \\ Dimensiones Psicosociales de Experiencias Culturalmente Marginales
}

LeOnaRdo Breno Martins

WELLINGTON ZANGARI

Gabriel TEIXEIRA DE MEDEIROS

\begin{abstract}
Resumo: Ao longo da história, sempre foram reportadas experiências pessoais "extraordinárias", relacionadas ao "paranormal". Contudo, tais experiências podem confrontar referenciais hegemônicos em dado contexto, além de conduzir à estigmatização de seus protagonistas, o que levanta questionamentos sobre que fatores e processos propiciam seu verificado crescimento. Para investigar variáveis psicossociais que intermedeiam relações entre crenças/experiências anômalas e cultura em contexto brasileiro, foram entrevistadas 46 pessoas que reportam contatos diretos com alegados "alienígenas", além de 35 que não as reportam, para comparação. A coleta e a análise dos dados delinearam uma pesquisa qualitativa-fenomenológica. Através da Teoria da Atribuição de Causalidade, averiguou-se que as experiências adquirem sentido sob uma mescla caracteristicamente contemporânea de referenciais científicos, esotéricos e religiosos tradicionais, o que permite seu fortalecimento mesmo diante da estigmatização que seus protagonistas sofrem na macrocultura enquanto insanos, mentirosos, ignorantes ou endemoninhados.
\end{abstract}

Palavras-chave: Cognição; Cultura; Estigma social.

Abstract: Throughout history, "extraordinary" experiences have always been reported, somehow related to the "paranormal". However, such experiences may confront hegemonic thinking in a given context, and lead to stigmatization of their protagonists, which raises questions about its growing. In order to investigate psychosocial variables that mediate the relation between beliefs/anomalous experiences and culture in the Brazilian context, 46 people were interviewed about their alleged contacts with aliens, such as 35 people that did not report such experiences, for comparison. Data gathering and analysis delineated a qualitative-phenomenological research. Using the Theory of Attribution of Causality, it was found that the experiences acquire meaning under a characteristically contemporary combination of scientific, esoteric and traditional religious references, allowing their strength even in face of the stigmatization that protagonists suffer in macroculture while insane, liars, ignorant or possessed.

Keywords: Cognition; Culture; Social stigma.

Resumen: Por la historia, siempre se registraron experiencias extraordinarias relacionadas con el "paranormal". Sin embargo, estas experiencias pueden entrar en conflicto con referencias culturales hegemónicas en una cultura, y conducir a la estigmatización de sus protagonistas, lo que plantea interrogantes sobre su crecimiento. Para investigar las variables psicosociales que median las relaciones entre las creencias/experiencias anómalas y la cultura en el contexto brasileño, fueron entrevistados 46 personas que reportaron el contacto directo con supuestos "extraterrestres" y 35 que no reportaron para comparación. La recolección y análisis de datos definen una investigación cualitativa fenomenológica. A través de la Teoría de la Atribución de la Causalidad, se ha encontrado que las experiencias adquieren sentido en una mezcla propiamente contemporánea de referencias científicas, esotéricas y religiosas tradicionales, lo que permite su fortalecimiento, incluso contra el estigma de que sus protagonistas sufren en la macrocultura como locos, mentirosos, ignorantes o que éste posea.

Palabras-clave: Cognición; Cultura; Estigma social.

\footnotetext{
Trabalho derivado da dissertação de mestrado do primeiro autor, intitulada: Contatos imediatos: investigando personalidade, transtornos mentais e atribuição de causalidade em experiências subjetivas com óvnis e alienígenas, Instituto de Psicologia, Universidade de São Paulo.

2 O primeiro autor agradece ao Conselho Nacional de Desenvolvimento Científico e Tecnológico (CNPq) pela bolsa concedida para a realização da pesquisa que possibilitou este artigo.
} 


\section{Introdução}

Experiências extraordinárias sempre foram reportadas ao longo da história. Conforme o contexto cultural, tais episódios subjetivos recebem interpretações distintas e não raro intercambiáveis, de modo que "êxtase místico", "experiências fora do corpo", "experiências de quase-morte”, lembranças de "vidas passadas", "curas espirituais" e "telepatia” são apenas exemplos extraídos de um universo significativamente maior de interpretações. O recente termo "experiências anômalas" agrega esses diferentes tipos de episódio e os define como experiências subjetivas em algo divergentes das experiências ordinárias ou do consenso usual em uma cultura sobre o que é possível ocorrer, embora não possuam relação obrigatória com patologia ou anormalidade (Cardeña, Lynn \& Krippner, 2014).

Assim, o reconhecimento de determinada experiência como anômala possui um determinante cultural decisivo. O que é anômalo em determinados contextos pode não sê-lo em outros. Em um exemplo antropológico clássico, uma cura tida como convencional na cultura médica ocidental foi considerada anômala pelo indígena australiano lembrado por Lévi-Strauss (1975), cuja debilitação lhe fora alegadamente infringida por feitiçaria, algo, por sua vez, mais insólito para o "homem branco" europeu que para o aborígene. Destaca-se, pois, o papel das formas pelas quais os protagonistas das experiências (i.e., as pessoas que as vivenciam) e membros de seus círculos sociais as explicam.

Uma vez definidas como experiências subjetivas acessíveis ao investigador através de relatos de primeira-mão e indícios circunstanciais, sua investigação prescinde da crença ou descrença em referenciais religiosos, esotéricos, pseudocientíficos ou quaisquer outros que possam acompanhá-las ou fundamentá-las no cotidiano da cultura. Logo, enquanto eventos de ordem subjetiva, os dados e achados relacionados podem ser estudados como quaisquer outros dados com os quais a psicologia habitualmente lida (Almeida \& Lotufo, 2003).

Uma categoria de experiência anômala cujas variáveis culturais relacionadas são pouco compreendidas, especialmente no Brasil, onde quase não foram estudadas (Martins \& Zangari, 2012), diz respeito a alegadas visões de "objetos voadores não identificados" e "seres alienígenas”, além de experiências relacionadas, complexas e impactantes, como "sequestros" (conhecidos popularmente como "abduções") e "canalizações" de mensagens alegadamente alienígenas. Tais episódios serão aqui chamados simplesmente de "experiências ufológicas" (em referência ao termo consagrado pelo uso popular, "ufologia”) e apresentam elevada prevalência na população geral em diversos contextos culturais, variando entre 5\% e 25\%, conforme o critério para apurá-las (Dewan, 2006a; Hough \& Rogers, 2007-2008; Schuessler, 2000).

Por seu caráter insólito, as experiências anômalas podem afrontar referenciais culturais hegemônicos. Uma das questões que então se erguem diz respeito à compreensão de variáveis psicossociais que atuam para amoldar, justificar, amparar ou mesmo fundamentar experiências anômalas, uma vez que estas podem ser estranhas mesmo na cultura de origem. Assim, a inquietação inicial a motivar o presente estudo se sustentou na constatação informal, erguida ao longo de quinze anos anteriores de entrevistas conduzidas pelo primeiro autor junto a protagonistas brasileiros de experiências ufológicas, de que estes tendem a ser estigmatizados em seus círculos sociais (incluindo os mais imediatos) como loucos, mentirosos, ignorantes ou endemoninhados, este último entre seus pares em grupos religiosos. Contudo, quando optavam por não relatar suas experiências, a estigmatização aparentemente não ocorria. Ainda assim, um número significativo de experiências novas sempre fora reportado, e seus protagonistas pareciam resistir a circunscrever os episódios em referenciais culturais hegemônicos, preferindo explicá-los sistematicamente enquanto contatos com inteligências alienígenas, a despeito das mencionadas consequências sociais adversas. Ademais, ao contrário de então parecerem idiossincrasias de seus protagonistas, as experiências tendem a apresentar padrões altamente reincidentes dentro da mesma cultura e tipicamente desassociados a transtornos mentais (Appelle, Lynn \& Newman, 2014; Bullard, 1989; Dewan, 2006b; Jung, 1958/1988; Martins \& Zangari, 2012), o que sugere a possibilidade de vieses culturais, ainda que não hegemônicos. Portanto, cumpre investigar possíveis vetores psicossociais relativos às experiências e a relação entre esses e referenciais hegemônicos, de modo a compreender como as experiências não apenas parecem se manter, mas crescer em incidência ao longo dos anos, mesmo diante da persistente estigmatização de seus protagonistas.

Estudos estrangeiros fornecem outros indicadores da relevância psicossocial do tema. Entre eles, Dewan (2006b) considera as experiências ufológicas, em termos de mobilização social, a categoria mais importante de experiência anômala relativa ao aparecimento de luzes, devido a suas funções mitológicas e religiosas, ao extenso mosaico de crenças associadas, aos episódios em primeira-mão com variados níveis de profundidade, às teorias conspiratórias e apocalípticas que delas emergem e ao interesse coletivo por elas estimulado para temas como ciência e vida extraterrestre. Complementarmente, ao apurar as dimensões folclóricas tradicionais resgatadas e atualizadas pelas experiências ufológicas (e.g., as narrativas medievais de sequestros por seres mágicos), Bullard (1989) distingue o ícone óvni como a quintessência das lendas modernas.

Um modo particularmente profícuo de enfrentar a questão do suporte cultural dessas experiências ocorre por intermédio da Teoria da Atribuição de Causalidade (TAC). Presentemente, a TAC se configura em um somatório de contribuições teóricas de base cognitivista centradas na compreensão dos processos e referenciais 
culturais pelos quais as pessoas buscam explicar eventos e experiências de seu cotidiano. Os processos de atribuição tendem a incidir sobre episódios em algo novos ou atípicos, pois o conhecimento prévio não pode fornecer automaticamente explicações satisfatórias a respeito. As pessoas agem então como "cientistas ingênuos", buscando nexos causais para as experiências de vida a partir de sua idiossincrasia e da cultura, o que inclui sistemas de crenças, atalhos mentais, valores, medos, expectativas, aprendizados e outras formas de cognição social (cf. ampla revisão em Dela-Coleta \& Dela-Coleta, 2006).

Embora seus objetos de estudo mais convencionais sejam os comportamentos pontuais da própria pessoa e os alheios, a TAC passou a ser usada posteriormente como referencial para o estudo de temas diversos, dentre eles, experiências religiosas e anômalas. Ao proporem uma Teoria Geral da Atribuição, Spilka, Shaver e Kirkpatrick (1985) sintetizam:

1. As pessoas buscam explicar os eventos cotidianos atribuindo-lhes causas. Como os eventos podem possuir causas diversas e mesmo incompatíveis, o atribuidor terá de escolher entre elas ou hierarquizá-las. Em caso de um agente causal humano, as atribuições tendem a ser concentradas em características duradouras ou outras do agente, como tendências de personalidade, razões, intenções etc. As atribuições constituem, em parte, tentativas individuais de encaixe de eventos em amplos sistemas de crenças e significado culturalmente disponíveis.

2. O processo de atribuição seria motivado pelo desejo de predição e controle, pela necessidade de perceber os eventos como significativos, pela necessidade ou desejo de se proteger física e psicologicamente, e/ou para manter ou alimentar a autoestima.

3. Os processos de atribuição são iniciados diante de eventos que não podem ser automaticamente assimilados pelo sistema de crenças-significado do indivíduo, possuem implicações para o controle de consequências futuras e/ou atingem a autoestima.

4. Iniciado o processo, as atribuições específicas tendem a ser aquelas que melhor restaurem a coerência no sistema de crenças do atribuidor, favoreçam a autoestima e consolidem confiança em consequências futuras agradáveis ou controláveis.

5. O grau de percepção de uma atribuição potencial como satisfatória (com probabilidade, então, maior para sua escolha) varia de acordo com características do atribuidor, o contexto no qual a atribuição é feita, as características do evento que se tenta explicar e o contexto no qual o evento ocorre. Se os sistemas de crenças imediatamente disponíveis não mantiverem a coerência em face da experiência, outro sistema tenderá a ser buscado.

6. Entre as possibilidades culturais, sistemas de conceitos religiosos fornecem amplo conjunto de explicações significativas para eventos, assim como possibilidades também amplas para fortalecer a autoestima e o sentimento de controle sobre a realidade, tais como fé, orações, rituais diversos etc. Mesmo novos e estranhos eventos podem ser abarcados, elaborados, preditos e/ou controlados dentro desses sistemas.

Como exemplar no estudo específico das experiências anômalas a partir da TAC, Machado (2010) averiguou relações entre experiências anômalas do tipo extrassensório-motoras (i.e., alegadas "percepções extrassensoriais" e "psicocinesias"), bem-estar subjetivo, crenças e atitudes dos protagonistas. A autora discutiu o conjunto de crenças associadas às experiências (e.g., crenças em vida após a morte, paranormalidade, reencarnação, práticas alternativas) e suas relações com a visão maior de mundo dos protagonistas, incluindo concepções religiosas e não religiosas, além do impacto da relação entre crenças e experiências no cotidiano, incluindo atitudes e tomadas de decisão, para as quais a atribuição de causalidade às experiências desempenha papel decisivo. Isso porque o sentido que os protagonistas deram às suas experiências afetou significativamente seu bem-estar subjetivo, tomadas de decisão e outras crenças.

Por seu turno, Zangari (2007) investigou experiências anômalas precognitivas (i.e., alegadas percepções paranormais de eventos futuros) entre médiuns de Umbanda. A partir da TAC, concluiu que as experiências inicialmente consideradas anômalas encontraram na religião sua significação, de modo a depender das crenças religiosas prévias, em detrimento das características específicas das experiências. Assim, as alegadas aptidões precognitivas tenderam a ser atribuídas aos espíritos e não a eventuais capacidades mentais dos médiuns ou a explicações mais prosaicas.

Dados os aspectos cognitivos amplos que regem as atribuições causais, a TAC possibilita a compreensão de processos psicossociais pelos quais protagonistas de experiências ufológicas concluem ter se deparado com alienígenas, em vez de optarem por explicações mais prosaicas, culturalmente disponíveis, ou outras de ordem sobrenatural ou paranormal. Assim, torna-se possível investigar relações entre processos intra e intersubjetivos que permitem a manutenção e mesmo fortalecimento de experiências, crenças e alegações extraordinárias socialmente marginalizadas.

\section{Objetivo}

Este estudo pretendeu investigar variáveis e processos psicossociais e cognitivos que atuam na elaboração subjetiva de experiências anômalas caracteristicamente contemporâneas (relativas a "óvnis" e "alienígenas") e permitem sua manutenção e crescimento mesmo diante da estigmatização cultural que seus protagonistas sofrem na macrocultura. 


\section{Metodologia}

Utilizamos uma abordagem qualitativa, por meio de entrevistas semiestruturadas. Como parte de um estudo mais amplo que contemplou também outras variáveis não discutidas neste artigo, foram entrevistados 81 voluntários brasileiros, recrutados em centros urbanos da região sudeste, por meio de amostra de conveniência. $\mathrm{O}$ número total de participantes foi delimitado por sua disponibilidade durante o período de coleta de dados e pela saturação de informações nas entrevistas.

A amostra total está dividida em dois grupos: o primeiro, composto de pessoas que alegaram algum tipo de experiência ufológica, variando de experiências breves com supostos óvnis e/ou alienígenas (e.g., o aparecimento fugaz de uma luz estranha ou vulto) a contatos prolongados e amistosos com alienígenas ou abduções; e, o segundo grupo, composto de pessoas que alegam não ter tido experiências ufológicas, de modo a usar suas atribuições sobre episódios do gênero como contraponto em relação aos protagonistas.

O critério de inclusão no primeiro grupo (pessoas que alegam algum tipo de experiência ufológica) foi a existência de, ao menos, um relato de experiência ocorrida em vigília, independentemente de outras experiências em sonhos ou em estados alterados de consciência que elas viessem a considerar como contatos com alienígenas. Aqueles que relatavam experiências ufológicas apenas em sonhos ou outros estados alterados, foram excluídos desta pesquisa. Por sua vez, o critério de inclusão no segundo grupo foi a negação explícita de qualquer tipo de experiência subjetiva (em vigília ou não) que viessem a considerar como contatos com alienígenas. Ambos os grupos foram compostos de pessoas adultas, de 24 a 60 anos, de ambos os sexos. A tabela a seguir apresenta alguns dados demográficos coletados.

Tabela 1: Frequências absolutas e relativas dos dados demográficos

\begin{tabular}{|c|c|c|c|}
\hline \multicolumn{2}{|c|}{ GRUPOS } & \multirow{2}{*}{$\begin{array}{l}\mathbf{P}(\mathbf{n} / \%) \\
20 / 43,5\end{array}$} & \multirow{2}{*}{$\begin{array}{c}\text { NP (n/\%) } \\
15 / 42,9\end{array}$} \\
\hline Sexo & Masculino & & \\
\hline & Feminino & $26 / 56,5$ & $20 / 57,1$ \\
\hline \multirow[t]{8}{*}{ Idade (em anos) } & $18-23$ & - & - \\
\hline & $24-28$ & $5 / 10,7$ & $5 / 14,3$ \\
\hline & $29-34$ & $4 / 8,7$ & $4 / 11,4$ \\
\hline & $35-39$ & $9 / 19,6$ & $8 / 22,9$ \\
\hline & $40-45$ & $9 / 19,6$ & $8 / 22,9$ \\
\hline & $46-50$ & $6 / 13$ & $3 / 8,6$ \\
\hline & $51-55$ & $7 / 15,2$ & $3 / 8,6$ \\
\hline & $56-60$ & $6 / 13,1$ & $4 / 11,4$ \\
\hline \multirow[t]{4}{*}{ Escolaridade } & $2^{0}$ grau & $9 / 19,6$ & $6 / 17,1$ \\
\hline & $3^{0}$ grau incompleto & $2 / 4,4$ & $2 / 5,7$ \\
\hline & $3^{0}$ grau completo & $12 / 26$ & $9 / 25,7$ \\
\hline & $3^{0}$ completo + pós-graduação & $23 / 50$ & $18 / 51,4$ \\
\hline \multirow[t]{21}{*}{ Profissão } & Ensino & $3 / 6,5$ & $8 / 22,9$ \\
\hline & Operação de fiação & - & $1 / 2,9$ \\
\hline & Bioquímica & $1 / 2,2$ & - \\
\hline & Pedagogia & $2 / 4,3$ & $1 / 2,9$ \\
\hline & Cabeleireiro & $1 / 2,2$ & - \\
\hline & Advocacia & $2 / 4,3$ & $3 / 8,6$ \\
\hline & Contabilidade & - & $2 / 5,7$ \\
\hline & Fisioterapia & $1 / 2,2$ & $1 / 2,9$ \\
\hline & Estatística & - & $1 / 2,9$ \\
\hline & Engenharia & $2 / 4,3$ & $2 / 5,7$ \\
\hline & Eletrônica & $1 / 2,2$ & $1 / 2,9$ \\
\hline & História & $1 / 2,2$ & $1 / 2,9$ \\
\hline & Enfermagem & $2 / 4,3$ & - \\
\hline & Terapia Holística & $9 / 19,6$ & - \\
\hline & Administração & $3 / 6,5$ & $1 / 2,9$ \\
\hline & Medicina & $1 / 2,2$ & - \\
\hline & Publicidade & $1 / 2,2$ & $1 / 2,9$ \\
\hline & Psicologia & $1 / 2,2$ & $1 / 2,9$ \\
\hline & Serviço público & $3 / 6,5$ & $3 / 8,6$ \\
\hline & Análise fiscal & - & $1 / 2,9$ \\
\hline & Produção cultural & $1 / 2,2$ & - \\
\hline
\end{tabular}




\begin{tabular}{|c|c|c|c|}
\hline GRUPOS & & $P(n / \%)$ & $\operatorname{NP}(n / \%)$ \\
\hline \multirow[t]{9}{*}{ Profissão } & Informal & - & $1 / 2,9$ \\
\hline & Odontologia & $1 / 2,2$ & - \\
\hline & Geografia & $1 / 2,2$ & - \\
\hline & Estudante & $1 / 2,2$ & $1 / 2,9$ \\
\hline & Psicopedagogia & $1 / 2,2$ & - \\
\hline & Artes & $3 / 6,5$ & - \\
\hline & Comércio & $2 / 4,3$ & $5 / 14,3$ \\
\hline & Ourivesaria & $1 / 2,2$ & - \\
\hline & Antropologia & $1 / 2,2$ & - \\
\hline \multirow[t]{9}{*}{ Crença religiosa } & Múltiplos referenciais & $25 / 54,3$ & - \\
\hline & Católica & $10 / 21,8$ & $25 / 71,4$ \\
\hline & Evangélica & - & $1 / 2,9$ \\
\hline & Espírita & $3 / 6,5$ & $4 / 11,4$ \\
\hline & "Acredita em Deus" & $4 / 8,7$ & $2 / 5,7$ \\
\hline & Agnóstico & $1 / 2,2$ & $1 / 2,9$ \\
\hline & Cristão s/ maior especificação & $1 / 2,2$ & $1 / 2,9$ \\
\hline & Candomblé & $1 / 2,2$ & - \\
\hline & Ateu & $1 / 2,2$ & $1 / 2,9$ \\
\hline \multirow{8}{*}{$\begin{array}{l}\text { Escala de convicção subjetiva sobre a } \\
\text { realidade concreta da experiência ufológica }\end{array}$} & Convicção nula & - & - \\
\hline & Conviç̧ão muito baixa & - & \\
\hline & Convicção baixa & - & - \\
\hline & Convicção mediana & $2 / 4,3$ & - \\
\hline & Convicção alta & $1 / 2,2$ & - \\
\hline & Convicção muito alta & $3 / 6,5$ & - \\
\hline & Convicção absoluta & $39 / 84,8$ & - \\
\hline & Nenhuma das anteriores & $1 / 2,2$ & - \\
\hline TOTAL & & $46 / 100$ & $35 / 100$ \\
\hline
\end{tabular}

LEGENDA: P - Grupo de protagonistas; NP - Grupo de não protagonistas.

Os participantes foram abordados em ambientes ordinários, como comércio, locais públicos e uma "clínica holística”, e recrutados a partir de uma pergunta descritiva inicial, feita de modo casual: se a pessoa já havia visto algo incomum no céu ou no solo. Conforme a resposta inicial e perguntas de refinamento subsequentes e igualmente descritivas, os voluntários em potencial forneciam elementos para o reconhecimento ou não do recorte inicialmente pretendido para este estudo, relacionado a experiências ufológicas breves, abduções e contatos amistosos. Ou seja, tornava-se possível reconhecer candidatos potenciais para a inclusão no primeiro ou segundo grupos anteriormente citados. O primeiro autor, então, se apresentava enquanto pesquisador e o(a) convidava a participar do estudo mais amplo de onde foram derivados os dados aqui apresentados.

A pesquisa foi aprovada por comitê de ética e todos os voluntários assinaram um Termo de Consentimento Livre e Esclarecido. As entrevistas, de duração livre, foram gravadas em áudio, com duração média de uma hora e variação de vinte minutos a três horas. As perguntas eram referentes aos detalhes das experiências (e.g., local, duração, descrição dos óvnis e alienígenas, sequência de eventos que compõem a narrativa) e as explicações para a ocorrência do episódio (e.g., o que seria a luz ou criatura, por que ela teria aparecido, por que a pessoa foi escolhida para o contato). No caso dos voluntários que não reportaram experiências ufológicas, arguiu-se sobre a que se deveriam tais episódios reportados por outras pessoas, apresentados na mídia etc. Dada a ausência de estudos brasileiros sobre variáveis psicossociais subjacentes às experiências ufológicas, pretendeu-se implementar um enfoque qualitativo-fenomenológico, que permitisse abordar em detalhe as entrevistas.

Assim, ao utilizar uma abordagem fenomenológica por método de análise, o presente artigo busca descrever a experiência vivida pelo sujeito como esta se apresenta a ele, de modo a focar-se nas interpretações oriundas da experiência vivida (Martins \& Bicudo, 1989). Portanto, leva em consideração que o sujeito que vivencia a experiência possui uma construção de vida que a fundamentou (Sadala, 2004). Esse ser-no-mundo se relaciona com o mundo pré-dado, bem como com sua percepção de mundo e as percepções de outrem, de modo que não existam mundos distintos, mas uma composição entre tais aspectos, na construção do mundo fenomenal, por meio da relação com o mundo e com a intersubjetividade. Deste modo, a fenomenologia de Merleau-Ponty pode ser entendida como uma filosofia mundana, pois parte do ponto de vista da encarnação corporal e intersubjetiva "em mútua constituição com o mundo, com a história, com a cultura" (Moreira, 2004, p. 455). 
Utilizamos a análise de conteúdo, que permite emergir "núcleos de sentido" extraídos dos relatos dos participantes, por meio de orações expressivas de um discurso em relação ao tema investigado e sua relação com as demais entrevistas. As análises ocorreram ao longo de todo o estudo e foram divididas em diversas etapas. Primeiramente, logo após a entrevista, eram feitos breves diários de campo, contendo as principais ideias apresentadas pelo entrevistado. A essas eram ainda acrescidas notas intensivas acerca das percepções e sensações do entrevistado sobre a entrevista, a relação entrevistador-entrevistado e o conteúdo da entrevista. As entrevistas foram analisadas inicialmente, relevando e listando todas as categorias encontradas em cada entrevista (Moustakas, 1994). Essas categorias foram arranjadas em grupos de unidades de sentido, os quais nortearam a análise das entrevistas (Gomes, 2010) e permitiram observar como cada categoria se relacionava à totalidade do discurso, a fim de distinguir as categorias centrais das periféricas (Ryan \& Bernard, 2003). Essa análise de associação de categorias permite verificar quais ideias são constantemente apresentadas em união, de modo a concorrer a um maior entendimento sobre as percepções e sentidos dados pelos entrevistados. Por fim, terminada essa construção de categorias, eram feitas duas descrições sobre a entrevista, ressaltando os pontos considerados mais importantes, uma primeira descrição sobre o que fora vivenciado como experiência ufológica e seus efeitos posteriormente sentidos, e uma segunda descrição sobre como tal fenômeno ocorreu e suas atribuições por parte de seus protagonistas. Ao fim das etapas supracitadas, um último escrito foi composto, de modo a incorporar ambas as descrições, a fim de descrever a experiência vivida por cada entrevistado (Creswell, 2012). Munido de todas as descrições de experiências, os entrevistados foram divididos, em cada bloco de resultados, a partir de suas similaridades e divergências, por meio de uma análise nomotética, desvelando os invariantes do fenômeno estudado e tematizando as convergências (Sadala, 2004) que são interpretadas, então, à luz dos estudos a respeito das experiências ufológicas. Divididos em subgrupos, uma nova e mais aprofundada análise foi realizada a partir das categorias destacadas. Devido à diversidade e singularidade dos entendimentos, essa análise se situou nas nuances singulares apresentadas para um mesmo entendimento, de modo a expor a similaridade sem, contudo, abandonar o caráter sui generis de cada entendimento.

\section{Resultados}

Os resultados a seguir serão agrupados conforme os dois grupos centrais de participantes da pesquisa: protagonistas e não protagonistas de experiências ufológicas. Assim, as atribuições de causalidade dos dois grupos serão inicialmente consideradas de forma distinta, propondo-se o embate entre ambas na discussão dos resultados.

\subsection{Protagonistas}

As descrições das experiências ufológicas a seguir emergiram imbuídas de atribuições causais, tanto nos termos usados quanto nos detalhamentos e justificativas. Salvo quando expresso em contrário, os trechos citados de entrevistas não constituíram exceções, mas pontos de vista comuns dentro das amostras, o que lhes confere um caráter de representatividade. Assim, para não tornar a exposição exaustiva, serão fornecidos apenas alguns exemplos de cada atribuição.

As experiências tenderam a ocorrer em estado vigil de consciência, à exceção dos contatos amistosos prolongados, os quais muitas vezes ocorreriam em estados alterados de consciência que contemplam "experiências fora do corpo”, sonhos, "canalização” (i.e., conteúdos mentais compreendidos pelos protagonistas como mensagens telepáticas enviadas pelos alienígenas), intuições, visualizações em processos meditativos, entre outros recursos alternativos. Por sua vez, embora experiências de abdução tendam a ser descritas como intrusivas, diferentemente dos contatos amistosos, geralmente descritos como agradáveis; em reiterados casos ambas experiências foram reportadas pela mesma pessoa.

Um aspecto destacado na elaboração das experiências é o pluralismo e mesmo o sincretismo dos sistemas de crença utilizados, podendo ser reconhecidos referenciais científicos (e.g., noções sobre física e cosmologia), religiosos (particularmente variações do cristianismo e de religiões orientais) e de esoterismo contemporâneo, o que Magnani (1996) chama de neoesoterismo (e.g., "confederação cósmica”, resgate dos instintos). Assim, enquanto a origem extraterrestre das experiências foi quase unânime, a definição dos termos "alienígena", "extraterrestre" e seus sinônimos, além de suas motivações (expostas adiante) combinam múltiplos referenciais.

\subsubsection{Alienígenas}

Os alienígenas responsáveis pelos óvnis são frequentemente entendidos como entidades materiais, vindas de outros planetas a bordo de naves mecânicas. Uma bioquímica belorizontina de 38 anos, sem religião específica, definiu os alienígenas que praticariam abduções como "seres assim altamente evoluídos tecnologicamente... São cientistas espaciais... Eles querem fazer experimentos com a gente, igual a gente faz com camundongos".

Para alguns entrevistados, a natureza dos alienígenas seria essencialmente dual: material e imaterial. Exemplarmente, um dentista mineiro de 31 anos, pós-graduado e que se define como "espiritualista", relata experiência ocorrida após um grave acidente automobilístico: "várias pessoas morreram nesse acidente, eu fiquei parado [no engarrafamento]... Saiu uma luz da montanha... começou lenta e entrou em uma velocidade muito alta e sumiu... 
Com certeza, acho que [a nave] foi resgatar pessoas ali [a alma dos que morreram no acidente]”.

Recorrendo a termos reincidentes nos contextos investigados, tais capacidades duais refletiriam a condição "evolutiva” (sic) dos alienígenas, entendida como o crescimento espiritual obtido através de um longo histórico de encarnações, evidenciando o referencial espírita kardecista. Justamente por sua elevada condição espiritual, algumas raças alienígenas estariam em contato com os protagonistas, para auxiliar na evolução espiritual da "humanidade terrestre" (sic), o resgate de suas dimensões intuitivas e sua futura participação em alguma forma de “confederação cósmica” (sic).

Como outro exemplo de referenciais esotéricos, diversos protagonistas identificaram as entidades contatadas, especialmente nos episódios prolongados, com os mestres ascensos de Helena Blavatsky, que comporiam a Grande Fraternidade Branca, tal como o fazem contatados em outros países (Melton, 1995). Assim também, em uma clínica holística onde foram acessados alguns dos protagonistas deste estudo, as práticas alternativas de cura propostas tinham associação à orientação direta de alienígenas, pertencentes ou subordinados ao conjunto dos referidos mestres.

\subsubsection{Motivos para as experiências}

Quanto aos motivos pelos quais os entrevistados teriam protagonizado as experiências, é possível sintetizar duas grandes tendências: (1) Casualidade e (2) Mérito dos protagonistas/escolha de forças superiores. Essa segunda perspectiva está, em diversos casos, associada a referenciais religiosos e/ou esotéricos, de modo que os voluntários foram escolhidos para o contato pelos alienígenas ou mesmo por um plano divino ao qual os alienígenas também estariam subordinados. Assim, os protagonistas teriam trilhado um caminho de evolução espiritual para se relacionarem com os alienígenas de modo favorável a tais metas elevadas junto à humanidade. Com frequência, contatados acabam reunindo grupos de pessoas que os tomam como lideranças espirituais evoluídas. Um contatado de 51 anos, ortopedista com pós-graduação e terapeuta holístico, exemplifica: "As duas consciências [seus guias extraterrestres] entendem cada vez mais se posso ou não ser o porta-voz dessa verdade... Eles falaram: 'vocês [ele e a esposa] serão uma frente mundial'”.

Em contrapartida, a casualidade tende a ser sugerida por protagonistas afiliados a religiões tradicionais ou sem grande preocupação religiosa ou esotérica. Um técnico em eletrônica mineiro de 44 anos, católico, apresenta essa ideia de modo representativo: "Quem viu primeiro [0 óvni] foi [diz o nome de um amigo]... Eu vi porque ele me mostrou... todo mundo que saiu do cinema naquele dia, naquela sessão, viu”.

\section{Realidade e racionalidade}

Acerca da convicção dos protagonistas sobre a "realidade objetiva" das experiências, virtualmente todos os entrevistados reportaram inicialmente buscar explicações prosaicas e, a seguir, questionar sua própria confiabilidade enquanto testemunha. Uma antropóloga de 41 anos, com pós-graduação e sem religião definida, exemplifica: "A gente duvida, mesmo com todo o conhecimento [esotérico] que a gente está adquirindo... Eu me perguntava muito: 'Será que é verdade? Será que eu vi?'”

Apenas após esses dois momentos (que poderiam ser superados em poucos instantes ou após dias ou semanas de elaboração) viria a perdurável convicção sobre a realidade objetiva da experiência, ainda que altamente insólita. E mesmo com tal convicção, tende a permanecer uma postura em algo crítica diante do que, em última instância, teria sido testemunhado e diante das experiências de terceiros. Uma auxiliar de enfermagem mineira de 45 anos exemplifica: "É uma coisa diferente... eu acho que [disco voador] é um nome, uma coisa estranha... eu não posso explicar... realmente eu não sei explicar, eu só sei falar o que eu vi”.

Dentre os protagonistas com predileções esotéricas, uma ambiguidade surge na referida busca pela pureza primitiva, de modo que a "racionalidade" tendeu fortemente a ser considerada ruim ou contrária à evolução espiritual. Nos termos reincidentemente usados nos contextos investigados, a postura ideal seria se "entregar, sem resistência” (sic) à intuição e à crença. Uma psicóloga belorizontina de 58 anos revela o conflito interno diante de suas dúvidas sobre a experiência: "Embora eu esteja querendo quebrar essa racionalidade e ficar mais no ceder e no sentir, eu ainda sou muito racional". Nas palavras exatas ditas por vários membros dos grupos investigados, "é crer pra ver".

Entre os desdobramentos do exposto, eventos interpretados na macrocultura enquanto usuais ou de pouca importância tendem a ser vistos pelos protagonistas, especialmente os que relatam contatos amistosos prolongados, como alusivos a algo excepcional. Como exemplos, círculos de uma luminosidade opaca em fotografias, passíveis de explicação como reflexos do flash da câmera em partículas suspensas de poeira e água, diversas vezes foram considerados "provas" da presença de "seres sutis" ou "sondas extraterrestres" (sic) ao seu redor. Episódios que usualmente seriam entendidos como sonhos e imagens mentais simples foram considerados manifestações dos alienígenas amigáveis, entre copiosos exemplos.

As experiências de todos os tipos tenderam fortemente a ser consideradas como construtivas, ampliando a visão de mundo dos protagonistas e possibilitando uma ressignificação da vida em direção a valores humanitários e a possibilidades metafísicas como a vida após a morte e outros planos de existência. Um abduzido fluminense de 49 anos, ourives, fornece exemplo recorrente: 
A gente, depois de ter essas experiências, pensa nessa possibilidade do cosmos ser habitado, de vida além da Terra, que a gente é só um pontinho no universo... Eu comecei a perceber que a gente tinha que amar mais o planeta, amar mais o próximo... É um planeta só. A gente tem que amar o planeta. É uma humanidade só.

Muitos entrevistados, especialmente quando organizados enquanto grupo esotérico, relataram terem sido, anteriormente, católicos, evangélicos, espíritas, candomblecistas, umbandistas e/ou frequentadores de diversos grupos, até que somente após encontrarem o grupo atual, teriam se reconhecido satisfeitos.

\subsection{Atribuições na ausência de experiências: os não protagonistas}

As entrevistas com pessoas que alegam não ter histórico de experiências ufológicas forneceram contraponto para as atribuições causais dos protagonistas. Tais atribuições dos não protagonistas, inclusive, coincidem com as dos familiares e amigos dos protagonistas, conforme os protagonistas reportaram.

\subsection{As origens das experiências dos protagonistas}

Duas grandes categorias emergiram na ausência de experiências, incluindo meios-termos entre ambas. De um lado, fenômenos conhecidos são elencados enquanto causas, como farsas, fantasias, insanidade e erros de interpretação de eventos naturais ou artificiais humanos (e.g., astros observados em condições incomuns, aviões, balões, alucinações). Uma professora paulista agnóstica de 30 anos exemplifica:

Eu acredito que muitas vezes as pessoas podem se enganar ou acreditar ter visto uma coisa que, na verdade, era outra coisa, ou imaginar ter visto alguma coisa, interpretar alguma situação que para elas foi real com uma interpretação pessoal, baseados nas suas crenças e na cultura que elas vivem.

As reincidentes atribuições estigmatizantes surgiram em termos como postos por uma comerciante mineira de 39 anos: "Eu acho engraçado. Eu acho que é muita imaginação... ou está com algum problema precisando resolver [faz um gesto, sugerindo transtorno mental]". Usualmente, tais respostas foram proferidas entre risos e expressões faciais contorcidas e jocosas.

A segunda categoria encontrada baseava-se em defender a origem alienígena das experiências, como o fez uma secretária escolar católica de 40 anos, mineira:
Eu acho que existe. Pela descrição que eles falam, não tem como não ser... Um ser mesmo de outro planeta... Deve ser alguma coisa assim semelhante a nós, mas que está para o outro lado, e com inteligência... Pelo que descreveram de objetos assim, de estarem voando, de haver luzes e tal, é uma coisa assim que foi desenvolvida, e pra desenvolver tem que ter inteligência.

Quando perguntados sobre o porquê de não terem tido eles mesmos experiências ufológicas, as respostas oscilaram entre três tendências: (1) Casualidade e (2) Escolha dos alienígenas, entre os que acreditam na origem alienígena dos episódios, e (3) Não susceptibilidade, entre os que consideravam as experiências farsas ou erros de interpretação de fenômenos conhecidos. Exemplificando, (1) "Uma vez eu estava na Serra do Cipó [na região metropolitana de Belo Horizonte]... Quando eu acordei, o pessoal falou que tinha um objeto no céu... Então alguma coisa aconteceu, só que eu estava dormindo" (engenheiro católico mineiro, 51 anos). (2) "Tem pessoas que tem mais afinidade com o assunto ou com 'eles' próprios [os alienígenas], e tem pessoas que 'eles' já veem grossamente que não têm condições de manter o contato" (professora aposentada mineira de 53 anos, espírita). (3) "Eu não tenho esse pensamento aberto para acreditar nisso... Para você acreditar nisso, você tem que ter uma imaginação muito grande!" (fisioterapeuta mineira de 49 anos, católica).

\subsection{Protagonistas e não protagonistas}

\subsubsection{Os papéis da ciência: validação e contraposição}

Os conceitos científicos que participam das atribuições são tipicamente apresentados de modo simplificado e apartados dos contextos teóricos que lhes conferem sentido no meio acadêmico. A ciência tende então a desempenhar um papel ambíguo, ora evocada para validar as experiências e crenças (e.g., "a física quântica explica tudo [os supostos feitos extraordinários dos alienígenas]"; "os astrônomos descobrem planetas novos todo dia" [para justificar a pluralidade de vida no universo]), ora rebaixada, quando confronta seus sistemas de crença, ao sugerir explicações prosaicas para as experiências ou a pouca plausibilidade de muitas alegações (e.g., "a ciência humana é muito limitada"; "os cientistas são muito arrogantes").

\section{Discussão}

As entrevistas e relatos aqui sumarizados permitem diversas considerações. As experiências ufológicas, especialmente quando mais complexas, possuem um caráter 
afrontoso e mesmo caótico na macrocultura. Sua atipicidade as torna alvos para atribuições causais, pelas quais protagonistas e seu meio social buscam conferir sentido, controle e previsibilidade a tais eventos e à realidade como um todo, de modo a diminuir a ambiguidade e a insegurança, possibilitar inferências e fortalecer a autoimagem (Dela-Coleta \& Dela-Coleta, 2006). As atribuições acabam por desempenhar esse papel, pois eventos ambíguos, de aparência extraordinária e potencialmente ansiogênica acabam por ser significados e harmonizados diante das expectativas, conhecimentos prévios, sistemas de crença, memórias e valores das pessoas.

\subsection{O comportamento dos protagonistas}

As atribuições causais internas, isto é, quando se atribui o evento a disposições de personalidade e outras centradas na pessoa (Heider, 1958), se apresentam fortes entre os protagonistas e na cultura geral, que, predominantemente, explicam as experiências ufológicas enquanto idiossincrasias dos primeiros (tanto ao não acreditar na realidade "objetiva” das experiências quanto ao considerá-los pessoas mais atentas ou "sintonizadas" - sic - com os alienígenas). Por sua vez, as atribuições causais externas, isto é, focadas no contexto onde estão os indivíduos (Heider, 1958), também ocorrem, como exemplificam as citadas atribuições relativas à casualidade, nas quais as experiências ocorreriam por acaso ou sorte.

O modelo de covariação de Kelley (1967) permite refinar a questão diante dos diferentes arranjos entre consenso, distintividade e consistência. No modelo, as atribuições internas tendem a ser feitas quando o consenso e a distintividade são baixos, enquanto é alta a consistência. Assim, é comum que pessoas que não protagonizaram experiências ufológicas considerem a ampla disseminação do tema óvni contrastante com o que pensam ser uma baixa proporção de relatos na cultura (ou seja, haveria um baixo consenso), além de entenderem que os protagonistas são pessoas usualmente estranhas, muitas vezes apenas por professarem as experiências (baixa distintividade, pois tais experiências ufológicas não seriam distintas de outras idiossincrasias dessas pessoas) e se interessar sempre pelo assunto (alta consistência em seu comportamento diante do tema).

Raciocínio semelhante, tanto entre protagonistas quanto para não protagonistas dessas experiências, poderia abarcar os casos em que o mérito dos primeiros é considerado diante do fenômeno tido como real, pois os protagonistas estariam mais sintonizados ou evoluídos que as demais pessoas (baixo consenso na população sobre como se comportar diante dos alienígenas), seriam pessoas especialmente benevolentes e evoluídas em diversas situações (baixa distintividade entre manifestações sugestivas de sua "evolução" diante de diversos domínios da vida) e enxergariam a presença alienígena em toda sorte de eventos sutis, incluindo outras formas de experiências anômalas professadas (alta consistência desse comportamento).

Ainda de acordo com o modelo de covariação (Kelley, 1967), a atribuição externa (e.g., arbitrariedade dos alienígenas) ocorre (ao se julgar os protagonistas) pelo equilíbrio das três fontes de informação, como quando se considera que qualquer pessoa que tivesse vivenciado um contato reagiria de forma intensa e transformadora, ao mesmo tempo em que tal afetação não ocorrera antes, mas somente nesse contexto (consenso, distintividade e consistência altos). Finalmente, o acaso enquanto atribuição situacional ocorreria diante da consideração de baixa consistência (e.g., os alienígenas estariam se manifestando com grande frequência, mas o protagonista os notou poucas vezes) e indefinição quanto às demais fontes (e.g., cada protagonista se comporta de um jeito; alguns acreditam, outros não).

\subsection{O comportamento dos alienígenas}

Para aqueles que concluíram pela natureza extraordinária dos óvnis, os comportamentos dos alienígenas também passam a ser objeto de atribuições. Assim, os alienígenas se apresentariam furtivos e escolheriam cada pessoa para contato devido a: (1) critérios que lhes são próprios ou que dominam, constituindo uma atribuição interna para os que consideram que os alienígenas deveriam se revelar publicamente tal como, por exemplo, os europeus fizeram no período das grandes navegações (consenso baixo diante da possibilidade de se apresentarem abertamente), ao invés de permanecerem décadas ou séculos agindo furtivamente (consistência alta do comportamento furtivo), a despeito do quanto as sociedades terrestres teriam mudado desde então, a ponto de já poderem aceitar mais facilmente a revelação da presença alienígena (distintividade baixa em relação às diferentes circunstâncias em que a furtividade faria ou não sentido em ser mantida).

Por sua vez, (2) outros consideram que os alienígenas não se apresentam abertamente e seguem com discrição seus planos por razões externas a eles, como a condição "pouco evoluída" (sic) da humanidade. Assim, coerente com referenciais esotérico-ufológicos com os quais estabeleceriam relações dialéticas, tais atribuições externas tendem a pregar que todas as civilizações alienígenas aqui presentes têm conosco semelhante cuidado e distanciamento (consenso alto), agindo assim por décadas ou séculos (consistência alta), ao contrário de como eles devem agir em relação a outras civilizações ou entre eles próprios (distintividade alta diante da especificidade da humanidade em comparação a outras civilizações).

Por fim, (3) em sintonia com Marçolla e Mahfoud (2002), algumas atribuições situam as experiências ufológicas no campo do mistério insondável, de modo a 
faltarem palavras e explicações refinadas por parte dos atribuidores. Assim, desenha-se uma atribuição situacional, diante da aparente ausência de padrões claros nas experiências (consistência baixa) e ausência de convicções razoáveis sobre os demais parâmetros.

\subsection{Experiência e cultura}

A pluralidade de referenciais a partir dos quais os protagonistas elaboram as experiências e sua história de vida estabelecem outra conexão com experiências ufológicas em outros países. Balch (1995) utiliza o termo "homem proteano" (protean man) para compreender um famoso grupo de contatados norte-americano. $\mathrm{O}$ adjetivo proteano alude ao deus grego Proteus, capaz de mudar de forma. Assim, o "homem proteano" experimentaria fraca adesão e constante fluxo entre diferentes referenciais e grupos. Tal como os contatados estudados por Balch, vários protagonistas deste estudo reportaram longo histórico de busca pessoal por um sistema de crenças-significado que julgassem satisfatório. Contudo, é importante ressalvar que o contexto brasileiro, por sua pluralidade cultural e seu sincretismo particularmente rico, favorece a experimentação de referenciais diversos, o que problematiza a pronta aplicação do conceito de "homem proteano" para sinalizar, como pretende originalmente o conceito, uma característica individual dos contatados. O vetor cultural justifica, ao menos em ampla medida, o trânsito ativo entre diferentes referenciais.

Como sugerido por Lewis (1995) sobre os contatados, os referenciais utilizados pelos protagonistas para elaborar as experiências parecem refletir arraigados valores pessoais e culturais. Desse modo, ciência, religiões tradicionais e temas da Nova Era constituem referenciais destacados no cenário contemporâneo, ainda mais quando combinados das mais diversas formas. $\mathrm{O}$ grau de uso desses referenciais pode ser superficial ou profundo, a depender do contexto, dos conhecimentos e disposições dos protagonistas e do feitio das experiências.

Portanto, enquanto a esfera cultural maior oscila entre considerar os protagonistas como mentirosos, iludidos, transtornados, sortudos ("estavam no lugar e hora certos", sic), azarados ("lugar e hora errados", sic, como no caso de penosas abduções) ou escolhidos por critérios misteriosos, eles próprios acabam por ora compartilhar desses referenciais (como quando questionam a própria sanidade ou consideram a experiência fruto do acaso ou de arbitrariedade dos alienígenas), ora por se reconhecerem, egossintonicamente, enquanto parte ativa de um plano maior. Tende a incluir-se aqui a construção de um autoconceito totalizador, que resgata passagens obscuras da história de vida e as integra positivamente enquanto expiação e preparação para um destino maior (e.g., abusos sofridos na infância constituindo preparação espiritual para os contatos).
Pela pluralidade de referenciais culturais, a realidade maior sinalizada pelas experiências passa a harmonizar alienígenas, espíritos, aptidões humanas excepcionais e toda sorte de realidades sutis a facilitar o questionamento de valores e crenças convencionais da cultura mais ampla. As sete características apontadas por Saliba (1995, p. 41-48) para aproximar as experiências ufológicas do campo religioso se evidenciam presentes nas atribuições: os alienígenas tendem a ser misteriosos, transcendentes, sobrenaturais, perfeitos, salvadores, redefinidores da visão de mundo e fomentadores de evolução espiritual. Por sua vez, referenciais esotéricos e religiosos tradicionalmente assentados na Terra e em uma dimensão sobrenatural um tanto distante têm seus domínios multiplicados ao incluir, de modo aparentemente concreto e visualizável pela ciência (ou por representações desta), bilhões de galáxias, com bilhões de planetas cada, dimensões paralelas e épocas distantes entre os quais se poderia viajar. Ao mesmo tempo, a ciência acaba como representante do que há de mais terreno e limitado, quando defende o ceticismo e levanta ressalvas quanto às alegações ufológicas.

Tal relação entre referenciais e experiências não parece uma relação vertical daquelas em relação a estas, mas de mútua influência, pois tanto as experiências são traduzidas pelos crivos interpretativos historicamente datados, quanto validam, ampliam, inspiram e transformam esses crivos. As noções científicas, esotéricas e religiosas encontram nas experiências exemplos confirmadores e ampliadores, ao retratar a pluralidade de vida no universo, possibilidades tecnológicas de naves espaciais, interfaces entre consciência e matéria, capacidades paranormais de alienígenas e seus contatados terrestres, além de profecias apocalípticas e de salvação da alma. Em contrapartida, as experiências são consolidadas e ampliadas graças aos referenciais, de modo que luzes não identificadas são descritas e lembradas como naves espaciais pilotadas por inteligências complexas e que não raro possuem nomes e histórico pessoal, sonhos ambíguos se tornam contatos frontais com alienígenas, episódios de vida aparentemente anômalos ganham significado robusto, atribulações pessoais se tornam provações preparatórias para os contatos, entre outras tantas possibilidades. Assim, afigurar-se-ia uma relação dialética de progressiva complexidade entre as experiências e os referenciais que permitiria episódios e sistemas de crença progressivamente destoantes dos referenciais culturais partilhados pela maioria, mas muito significativos psicologicamente, o que favorece sua persistência e fortalecimento. Mesmo a estigmatização cultural passaria então a alimentar o sistema de crenças-significado e os episódios, pois atuaria como evidência adicional da grandeza das experiências, em contraste ao mundanismo depreciado por se associar a ceticismo, descrença e limitações humanas em geral. Ao discutirem relatos sobre luzes estranhas no município mineiro de Caeté, 
Marçolla e Mahfoud (2002) encontram semelhante fenômeno na relação complementar entre memórias individual e coletiva, de modo que a primeira resgata e presentifica a tradição, enquanto a segunda valida a primeira e preenche suas lacunas.

Ainda quanto à relação experiência-cultura, seria natural que experiências anômalas, independentemente de sua origem, fossem descritas em termos com que os protagonistas pudessem lidar, sem que houvesse, necessariamente, uma correspondência literal entre descrição e experiência original. Assim, a expressão "é como se" e semelhantes surgiram frequentemente nos relatos, sugerindo que as analogias não são exatas e que, mesmo com o uso de referenciais culturais e somado às ausências de atribuições, um grau de estranheza permanece.

Paiva (2007) evoca o conceito de contraintuições para tratar da aptidão universal da espécie humana para reconhecer a pretensa violação de princípios naturais como permanência do objeto, gravidade e outras noções que nas etapas iniciais do desenvolvimento do organismo se tornam naturalizadas. Nos campos de tensão entre intuições e contraintuições, somados à tendência natural em atribuir agentes causais, emergiriam as crenças e experiências religiosas. Assim, mecanismos inatos favoráveis à emergência de experiências religiosas (e potencialmente de experiências anômalas) encontrariam, na cultura, vias para sua elaboração, através da atribuição de agentes causais e situados entre o mundo material e o sutil, como, neste caso, seriam os alienígenas. Isso remete novamente à discussão de Marçolla e Mahfoud (2002) sobre luzes anômalas relatadas em Caeté, para os quais a dimensão do sagrado fornece à razão contexto para reconhecer plausibilidade nas experiências.

Dada a complexidade psicossocial das crenças e experiências ufológicas, reduzi-las à insanidade, falta de bom senso e atribuições afins parece exemplificar o que Ross (1977) chamou de erro fundamental de atribuição, que significa ignorar variáveis contextuais e executar, de modo simplista, uma atribuição interna para um comportamento, como relatar uma experiência ufológica.

Tal ampla estigmatização social dos protagonistas, expressa desde a jocosidade levemente desconfortável até a patologização literal, fornece elementos iniciais favoráveis à hipótese da pouca adequação cultural das experiências, que tende a ser revertida apenas no seio de grupos específicos e menores, como grupos de contatados e abduzidos, clínicas holísticas, grupos esotéricos e a "comunidade ufológica" (sic), que existe virtualmente sem a necessidade de convívio direto entre os interessados pelo tema. A busca por novas atribuições se insere então no contexto pela busca de conforto psicológico e autoestima, o que entrevistados reportaram não encontrar em seus antigos sistemas de crença e grupos, quando não somente se angustiariam pela falta de coerência entre os referenciais e as experiências, mas sofreriam estigmatização no seio dos grupos afins.
Isso também remete ao modelo de Spilka et al (1985), de modo que as atribuições religiosas inicialmente disponíveis aos protagonistas teriam sido checadas e confrontadas, quando então seriam consideradas insuficientes, ao menos sozinhas, dando início à busca por diversos referenciais congruentes com suas experiências anômalas. Possivelmente, é nessa lacuna de suporte da macrocultura que emerge o papel organizador psicológico de microculturas descobertas após laboriosa jornada de buscas, decepções e trocas. Ao que as entrevistas fartamente apontam, apenas a mescla de referenciais exercida nesses grupos permitiram o exercício satisfatório das funções das atribuições causais, entre as quais fortalecer a autoestima e conferir sentido e controle aos eventos.

\section{Considerações finais}

As experiências ufológicas mantêm sua conotação exótica tanto entre protagonistas quanto na macrocultura, $o$ que mobiliza o complexo processo cognitivo social das atribuições de causalidade. Enquanto os não protagonistas, predominantemente, realizam atribuições internas para as experiências dos protagonistas, o que possui uma dimensão estigmatizante, estes reagem à falta de amparo da cultura maior e buscam sentido, controle e manutenção da autoestima em sistemas de crença-significado tipicamente contemporâneos, mas pouco conhecidos na macrocultura, tanto que sua busca é laboriosa.

A complexidade das experiências ufológicas, enquanto fenômeno cultural, demanda novos estudos. Assim, os diferentes arranjos entre experiências e sistemas de crença-significado podem ser explorados, inclusive em contextos distintos dos abordados neste artigo (e.g., meios rurais), e pelo uso de métodos quantitativos e qualitativos. Somente uma articulação entre diferentes métodos e achados provenientes de diferentes contextos pode responder, em profundidade, ao enigma representado por experiências anômalas tipicamente contemporâneas.

\section{Referências}

Almeida, A. M. \& Lotufo Neto, F. (2003). Diretrizes metodológicas para investigar estados alterados de consciência e experiências anômalas. Revista de Psiquiatria Clínica, 30(1), 121-128.

Appelle, S., Lynn, S. J. \& Newman, L. (2000). Alien abduction experiences. Em E. Cardeña, S. J. Lynn \& S. Krippner (Eds.). Varieties of anomalous experience: examining the scientific evidence (p. 253-282). Washington, DC: American Psychological Association.

Bullard, T. E. (1989). UFO abduction reports: the supernatural kidnap narrative returns in technological guise. Journal of American Folklore, 102(404), 147-170. 
Cardeña, E., Lynn, S. J. \& Krippner, S. (Orgs.) (2014). Varieties of anomalous experience: examining the scientific evidence. $2^{\text {nd }}$ ed. Washington DC: American Psychological Association.

Creswell, J. W. (2012). Qualitative inquiry and research design: Choosing among the five traditions (3. ed.). Thousand Oaks, CA: Sage.

Dela-Coleta, J. A. \& Dela-Coleta, M. (2006). Atribuição de causalidade: teoria, pesquisa e aplicações. Taubaté, SP: Cabral Editora e Livraria Universitária.

Dewan, W. J. (2006a). Anomalous experiences in North Carolina: a survey. Journal of Popular Culture, 39(1), 29-43.

Dewan, W. J. (2006b). "A saucerful of secrets": an interdisciplinary analysis of UFO experiences. Journal of American Folklore, 119(472), 184-202.

Gomes, W. B. (2010). Relações metodológicas entre fenomenologia, historiografia e psicologia humanista. Revista da Abordagem Gestaltática, 16(1), 3-11.

Heider, F. (1958). The psychology of interpersonal relations. New York: Wiley.

Hough, P. \& Rogers, P. (2007-2008). Individuals who report being abducted by aliens: investigating the differences in fantasy proneness, emotional intelligence and the big five personality factors. Imagination, Cognition and Personality, 27(2), 139-161.

Jung, C. G. (1988). Um Mito Moderno sobre Coisas Vistas no Céu. Petrópolis: Vozes (Originalmente publicado em 1958).

Kelley, H. H. (1967). Attribution theory in social psychology. Em D. Levine (Ed.), Nebraska Symposium on Motivation (Volume 15, p. 192-238). Lincoln, NE: University of Nebraska Press.

Lévi-Strauss, C. (1975). O feiticeiro e sua magia. Em C. Lévi-Strauss. Antropologia estrutural (p. 193-213). Rio de Janeiro: Tempo Brasileiro.

Machado, F. R. (2010). Experiências anômalas (extra-sensório-motoras) na vida cotidiana e sua associação com crenças, atitudes e bem-estar subjetivo. Boletim da Academia Paulista de Psicologia, 30(79), 462-483.

Magnani, J. G. C. (1996). O neoesoterismo na cidade. Revista USP, (31), 6-15

Marçolla, B. \& Mahfoud, M. (2002). A luz verde do Morro Vermelho: a elaboração da experiência do sobrenatural em uma tradicional comunidade mineira. Psicologia em Revista, Belo Horizonte, 8(12), 83-94.

Martins, J. \& Bicudo, M. A. (1989). A pesquisa qualitativa em psicologia: fundamentos e recursos básicos. São Paulo: Moraes.

Martins, L. B. \& Zangari, W. (2012). Relações entre experiências anômalas tipicamente contemporâneas, transtornos mentais e experiências espirituais. Revista de Psiquiatria Clínica, 39, 198-202.
Melton, J. G. (1995). The contactees: a survey. Em J. R. Lewis (Org.). The gods have landed: New religions from other worlds (p. 1-14). Albany, NY: State University of New York Press.

Merleau-Ponty, M. (2006). Fenomenologia da percepção. 3. ed. (Moura, C. A. R. Trad.). São Paulo: Editora Martins Fontes.

Moreira, V. (2004). O método fenomenológico de Merleau-Ponty como ferramenta crítica na pesquisa em psicopatologia. Psicologia, Reflexão e Crítica, 17(3), 447-456.

Moustakas, C. (1994). Phenomenological research methods. Thousand Oaks, CA: Sage.

Paiva, G. J. (2007). Psicologia Cognitiva e Religião. Revista de Estudos da Religião, 1, 183-191.

Ross, L. (1977). The intuitive psychologist and his shortcomings: Distortions in the attribution process. Em L. Berkowitz (Ed.), Advances in experimental social psychology (volume 10, p. 173-240), Orlando, FL: Academic Press.

Ryan, G. W. \& Bernard, H.R. (2003). Techniques to identify themes. Field Methods, 15(1), 85-109.

Sadala, M. L. A. (2004). A fenomenologia como método para investigar a experiência vivida: uma perspectiva do pensamento de Husserl e de Merleau- Ponty. Em Seminário internacional de pesquisa e estudos qualitativos, 2., Bauru. Anais... Bauru: Universidade do Sagrado Coração de Jesus e Sociedade de Estudos e Pesquisa Qualitativa, $1 \mathrm{~cd}$ - rom.

Saliba, J. A. (1995). Religious Dimensions of UFO Phenomena. Em J. R. Lewis (Ed.) The gods have landed: new religions from other worlds (p. 15-64). Albany, NY: State University of New York Press.

Schuessler J. F. (2000). Public opinion surveys and unidentified flying objects. Morrison: Mutual UFO Network.

Spilka, B., Shaver, P. \& Kirkpatrick, L. A. (1985). A general attribution theory for the psychology of religion. Journal for the Scientific Study of Religion, 24(1), 1-20.

Zangari, W. (2007). Experiências anômalas em médiuns de umbanda: Uma avaliação fenomenológica e ontológica. Boletim Academia Paulista de Psicologia, 27, 67-86.

Leonardo Breno Martins - Possui Graduação em Psicologia pela Universidade Federal de Minas Gerais, Mestrado e Doutorado em Psicologia Social pela Universidade de São Paulo (USP). Pesquisador de Pós-Doutorado no Instituto de Psicologia da USP com financiamento da FAPESP (processo n 2015/20112-3), pesquisador do Laboratório de Psicologia Anomalística e Processos Psicossociais (Inter Psi) e do Laboratório de Psicologia Social da Religião (LabPsiRel), ambos da USP. Coordenador do Grupo de Estudos Interdisciplinares da Percepção e da Arte Mágica (IlusoriaMente), vinculado ao Inter Psi-USP. Endereço profissional: Inter Psi - Laboratório de Psicologia Anomalística e Processos Psicossociais. Instituto de Psicologia, Universidade de São Paulo. Av. Professor Mello de Morais, 1721, Bloco A, sala 111, Cidade Universitária USP, CEP 05508030, São Paulo, SP. E-mail: leobremartins@usp.br 
Gabriel Teixeira de Medeiros - Doutorando em Psicologia Social pela Universidade de São Paulo (USP). Possui Graduação em Psicologia pela Universidade Federal de São Paulo (UNIFESP) e Mestrado em Ciências Interdisciplinares da Saúde pela UNIFESP. Membro do Grupo de Pesquisa CNPq UNIFESP-USP: Corpo e Alma do Sujeito da Saúde (CASUSA), Membro do Laboratório de Pesquisa Social e do Grupo de Pesquisa - CNPq UNIFESP-UFSCar: Corpo, cognição e experiência nas ciências da mente, e membro do INTER PSI - Laboratório de Psicologia Anomalística e Processos Psicossociais (USP). Endereço profissional: Inter Psi - Laboratório de Psicologia Anomalística e Processos Psicossociais. Instituto de Psicologia, Universidade de São Paulo. Av. Professor Mello de Morais, 1721, Bloco A, sala 111, Cidade Universitária USP, CEP 05508030, São Paulo, SP. E-mail: gabriel_tmedeiros@yahoo.com

Wellington Zangari - Graduado em Psicologia pela Universidade Paulista, Mestre em Ciências da Religião pela Pontifícia Universidade Católica de São Paulo, Doutor em Psicologia Social pela Universidade de São Paulo e Pós-Doutorado em Psicologia Social pela USP, com estágio na Division of Personality Studies - University of Virginia. Professor do Departamento de Psicologia Social e do Trabalho do Instituto de Psicologia da USP; Vice-Coordenador do Laboratório de Psicologia Social da Religião e Coordenador do INTER PSI - Laboratório de Psicologia Anomalística e Processos Psicossociais, ambos ligados ao Departamento de Psicologia Social e do Trabalho do Instituto de Psicologia da Universidade de São Paulo. Atua como membro da Comissão de Orientação e Fiscalização do Conselho Regional de Psicologia de São Paulo. É membro do Grupo de Trabalho "Diversidade Epistemológica Não-hegemônica em Psicologia, Laicidade e Diálogo com Saberes Tradicionais (DIVERPSI)", alocado no Núcleo de Métodos e Práticas Psicológicas do Conselho Regional de Psicologia de São Paulo. Endereço profissional: Inter Psi - Laboratório de Psicologia Anomalística e Processos Psicossociais. Instituto de Psicologia, Universidade de São Paulo. Av. Professor Mello de Morais, 1721, Bloco A, sala 111, Cidade Universitária USP, CEP 05508030, São Paulo, SP. E-mail:w.z@usp.br

Recebido em 04.11.2016

Primeira Decisão Editorial em 24.12.2016

Aceito em 20.01.2017 